\title{
How Well Do Science Teachers Do? Differences in Teacher-Student Interpersonal Behavior Between Science Teachers and Teachers of Other (School) Subjects
}

\author{
Perry den Brok $^{*}, 1$, Ruurd Taconis ${ }^{1}$ and Darrell Fisher ${ }^{2}$ \\ ${ }^{I}$ Eindhoven School of Education, Eindhoven University of Technology, The Netherlands \\ ${ }^{2}$ Science and Mathematics Education Center, Curtin University of Technology, Australia
}

\begin{abstract}
The differences in teacher interpersonal behavior between science classes and other subject classes in secondary education are investigated using the Questionnaire on Teacher Interaction (QTI). Multilevel analysis of variance was used on an existing Dutch data set containing 44,353 students and 605 teachers. 8,503 students (19.2 percent) reported on science teachers. Science teachers were perceived as less dominant and less cooperative. Science teachers perceived themselves as less cooperative. Dominance and cooperation are known to be favorable for learning results and students' subject related attitudes. Hence, science teachers' different interpersonal behavior contributes to lower appreciation and higher perceived difficulty levels for students regarding the science subjects.
\end{abstract}

Keywords: Teacher-student interpersonal behavior, student perceptions, subject differences, interpersonal profiles, multilevel analysis.

\section{RATIONALE}

During the last 25 years various studies have been conducted on students' and teachers' perceptions of teacherstudent interpersonal behavior. Several of these studies have used the same framework to study these perceptions: the Model for Interpersonal Teacher Behaviour (MITB) $[1,2]$. This model maps (perceptions of) the teacher-student interpersonal relationship in terms of two, independent dimensions, Influence (the degree to which the teacher controls communication) and Proximity (the degree to which the teacher and students display closeness rather than opposition and conflict). The model is based on the work of psychologist Timothy Leary [3] which has been used in various research domains, such as education, psychology, pedagogy and communication. In education, studies starting from the MITB have also used the same research instrument, the Questionnaire on Teacher Interaction or QTI [1, 2]. These studies originate from a host of countries and address a variety of topics [4-16]. In fact, the number of studies investigating teacher-student interpersonal relationships using this instrument has been reported well over 120 and comprises research in more than 30 countries [17]. These studies have investigated links between teacher-student interpersonal relationships and student outcomes, links with perceptions of other teacher behaviors, have established interpersonal profiles, links with teacher non-verbal behaviors, have mapped the development of interpersonal behavior during the teaching career, have investigated the effects of student and teacher background characteristics such as gender, ethnicity, age, experience - class and school

*Address correspondence to this author at the Eindhoven School of Education, Eindhoven University of Technology, P.O. Box 513, 5600 MB Eindhoven, Building: Traverse 3.46, The Netherlands;

Tel: +31.40.2474702; Fax: +31.40.2475379; E-mail: p.j.d.brok@tue.nl characteristics - such as class or school size, ethnic and gender distribution, school type - on student perceptions of the teacher-student relationship and investigated links with assessment and educational innovations, among many other topics $[17,18]$.

Most of these studies have been conducted within secondary education and within the science subjects (math, chemistry, physics, biology), although other subjects have been studied as well $[19,20]$. However, studies comparing perceptions of teacher interpersonal behavior between different school subjects have been rare and in cases where subject taught was investigated, it was not the variable of central concern [21]. The present study compares perceptions of students (and teachers) of the teacher-student interpersonal behavior between science teachers and teachers of other school subjects.

Such a comparison may be interesting and relevant for a number of reasons. First, in many countries few students decide to pursue a career in science or mathematics and only a small number of students enroll in science classes [22, 23]. Although there may be many reasons for this, undoubtedly the teacher and his or her behavior will also play an important role. Research in the field of teacher-student interpersonal behavior unmistakably shows that perceptions of interpersonal behavior are related to subject-related attitudes such as pleasure, interest, effort, confidence and relevance $[9,17,20]$. If it can be shown that certain behaviors or styles are less prevalent among science teachers, this information can be used to start professional development activities or to make teachers become aware of these different styles.

Secondly, many students may have prototypical images or even stereotypical images (or prejudices) of science, scientists and science teachers. Taconis \& Kessels [24] 
found that science teachers are perceived less socially attractive and competent than teachers of other subjects. Such images may affect the way in which students interact with their teachers and the way they perceive this interaction. On the other hand, such images may also reflect the actual interaction patterns in classroom [25-27].

Third, science teachers themselves may have specific beliefs regarding their subject and the way it should be taught $[28,29]$. For example, there is some evidence that some teachers regard the knowledge of their subject as more absolute and of higher status compared with other subjects, which in turn may result in less student-directed and more subject-directed teaching styles [28]. This in turn may lead to different perceptions of interpersonal behavior by teachers themselves and by their students.

Finally, it has been suggested that the nature of school subjects may have a direct impact on the appropriateness or necessity of particular teaching interactions. Den Brok et al. [20] found in an in-depth study comparing 45 Physics teachers and 52 EFL (English Foreign language) teachers, that Physics teachers were rated lower on dominance than EFL teachers. His respondents indicated that in many EFL classes small tasks with many subtasks were used, requiring many corrections by teachers, and this was offered as an explanation for the relatively high score on dominance found for EFL teachers.

\section{THEORETICAL FRAMEWORK: TEACHER- STUDENT INTERPERSONAL BEHAVIOR}

The conceptualization of teacher-student interpersonal behavior as used in the present study has been described by Wubbels and Levy [30] and Wubbels et al. [17] in detail and we only summarize it here. The conceptualization is based on the perception of students (and teachers) of the behavior of the teacher. Students' perceptions are studied with the Leary-based [3] Model for Interpersonal Teacher Behavior $[1,2]$.

The model maps interpersonal teacher behavior along two dimensions: Influence (DS, Dominance - Submission) and Proximity (CO, Cooperation - Opposition). The Influence dimension represents the degree of dominance or control displayed by the teacher, while Proximity describes the level of cooperation between teacher and students. The two dimensions can be represented in a coordinate system divided into eight equal sectors (see Fig. 1). The sectors are labeled DC, CD, and so on, according to their position on the graph. The sectors of the model describe eight different behavior types: Leadership, Helpful/Friendly, Understanding, Student Freedom, Uncertain, Dissatisfied, Admonishing behavior and Strictness.

The Questionnaire on Teacher Interaction (QTI) was developed in The Netherlands in 1984 to gather student and

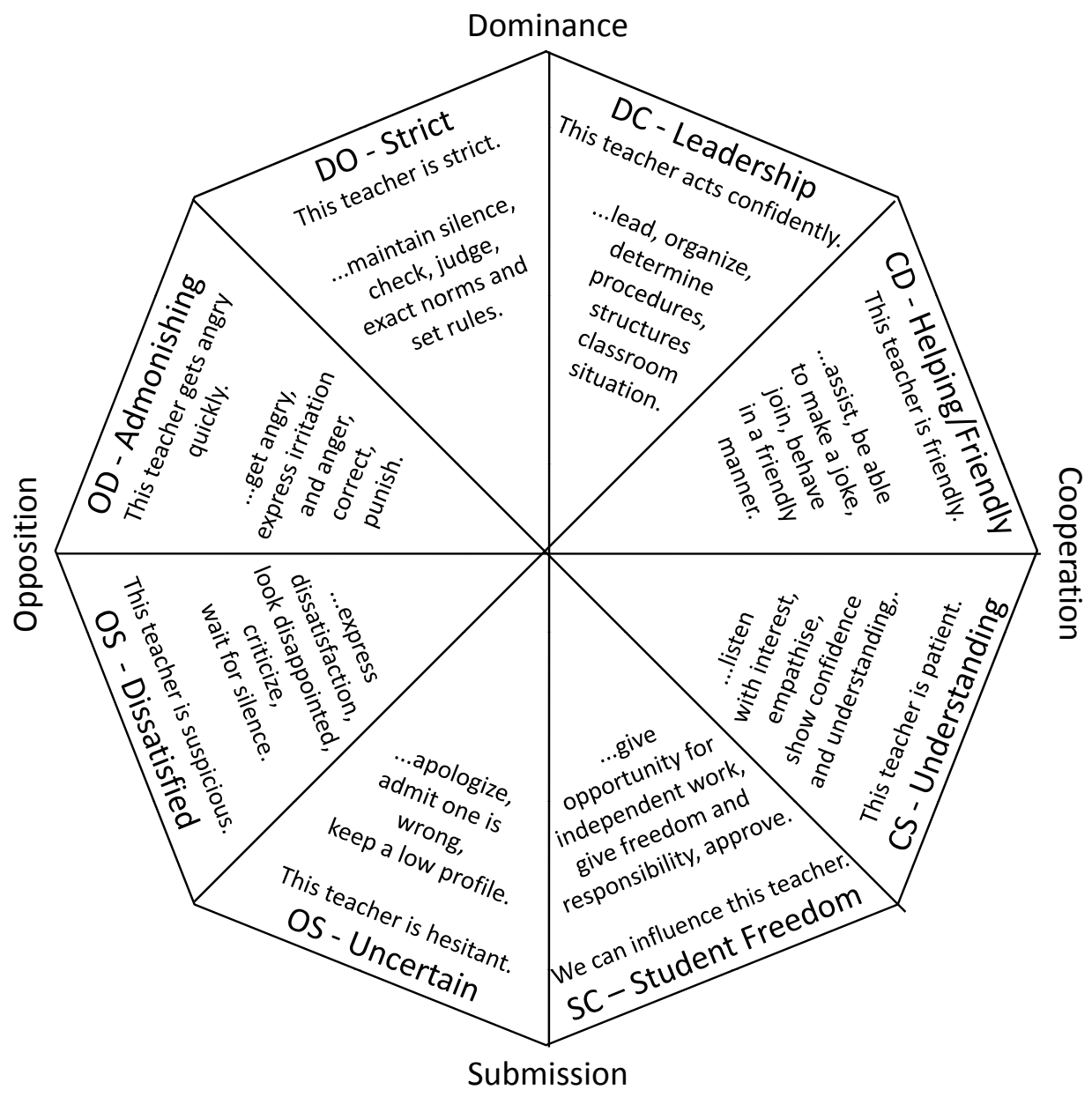

Fig. (1). The model for interpersonal teacher behavior. 
teacher perception data $[1,2]$ based on the Model for Interpersonal Teacher Behavior. Research with the QTI has resulted in a vast and evolving knowledge base on teacherstudent interpersonal behavior [17, 19, 21, 30].

Using data gathered with the QTI, researchers in The Netherlands derived a typology of interpersonal teaching styles $[31,32]$. A graphical display of the eight types is presented in Fig. (2). The eight types can be characterized by means of the two dimensions in the Model for Interpersonal Teacher Behavior (see Fig. 2). The Authoritative, Tolerant/Authoritative and Tolerant profiles are patterns in which students perceive their teachers relatively high on the Proximity Dimension, with the Tolerant type lowest on the Influence Dimension. Less cooperative than these three types are the Directive, Uncertain/ Tolerant, and Drudging profiles, with the Uncertain/Tolerant type lowest on the Dominance Dimension. The least cooperative pattern of interpersonal relationships is demonstrated by the Repressive and Uncertain/Aggressive types. Repressive teachers are the most dominant of all eight types.

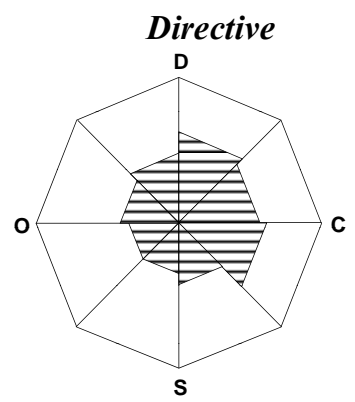

Key words:

well-structured; taskoriented; high standards; occasionally friendly Stud. attitudes: moderate Stud. achievement: high

\section{Uncertain/Tolerant}

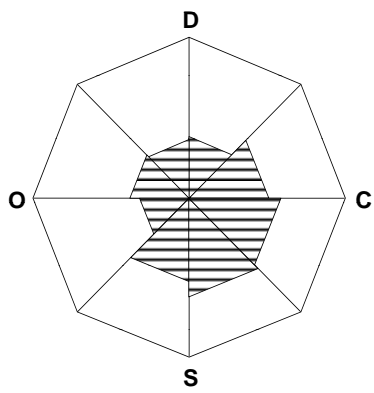

Key words:

Unstructured; not taskoriented; cooperative

Stud. attitudes: moderate

Stud. achievement: low

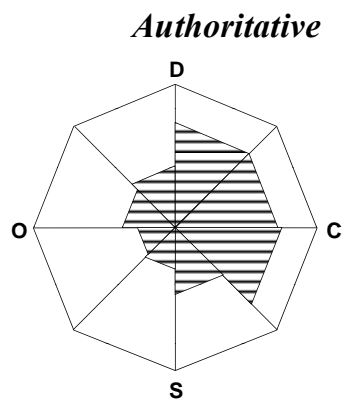

Key words:

well-structured; task-oriented; pleasant; personal interest in students; lecture

Stud. attitudes: high

Stud. achievement: high

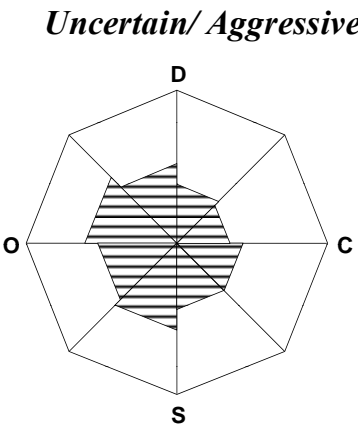

Key words:

Disorderly; not task-oriented; unbalanced teacher behavior; aggressive

Stud. attitudes: low

Stud. achievement: low

Various studies [33] have indicated that these types of patterns of interpersonal relationships relate to student's attitudes and student's achievement. The Directive, Authoritative and Tolerant/Authoritative styles are related to high student attitudes, while the Repressive style relates to low student attitudes. The Repressive style, however, is also associated with high student achievement. The Uncertain and Uncertain/ Aggressive styles are associated with low student achievement.

\section{SUBJECT-RELATED DIFFERENCES IN TEACHER- STUDENT INTERPERSONAL BEHAVIOR}

A small number of studies have investigated subjectrelated differences in students' and teachers' perceptions. In one study in the USA [21], using multilevel analysis and investigating a large number of other variables as well, differences were found in students' perceptions on QTI scale scores according to the subject taught. Students in science/math classes perceived their teachers lower on the Leadership (DC) and Understanding (CS) scales than

Tolerant/ Authoritative

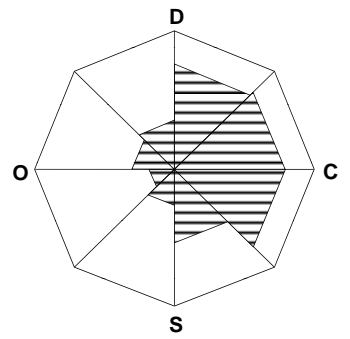

Key words:

Student freedom/ responsibility; occasional laughing; variety of methods Stud. attitudes: high Stud. achievement: high

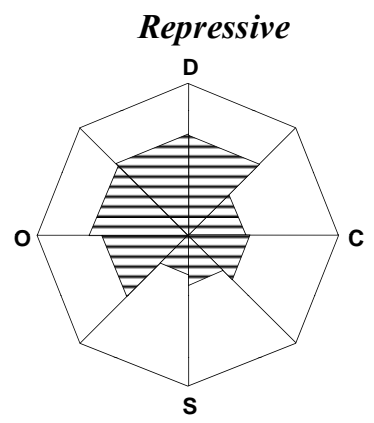

Key words:

Structured but not well organized, uninvolved docile students; unpleasant,

Stud. attitudes: low

Stud. achievement: high
Tolerant

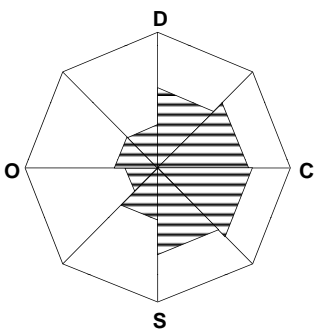

Key words:

Disorganized; students have some real power; individual work

Stud. attitudes: moderate Stud. achievement: high



Key words:

Teacher continuously struggles to manage the class; neither enthusiastic nor supportive nor competitive Stud. attitudes: low Stud. achievement: moderate

Fig. (2). Graphic representations and descriptions of the 8 types of patterns of interpersonal relationships. The associated performance is based on Brekelmans, Wubbels, \& Levy (1993). 
students in all other subjects, while students in social science classes (Geography, Economy, History) perceived their teachers as more Uncertain (SO) than students in all other subject classes. Effect sizes in the Levy et al. [21] study were strong and represented about half a standard deviation in scale scores.

Den Brok et al. [20] compared students' perceptions of Physics $(n=45)$ and English as a Foreign Language (EFL) teachers $(n=52)$ for two separate samples each concerning either of the subjects. Using only interpersonal dimension scores they found Physics teachers to be perceived as less cooperative and slightly less dominant than EFL teachers. They also found differential effects of teacher-student interpersonal behavior on student outcomes between the two subjects. Interpersonal behavior seemed to have a larger effect on pleasure and confidence for physics teachers, while for EFL teachers it had a larger effect on achievement scores and perceived relevance of the subject. Influence was (slightly) positively related to achievement with physics, and substantially positively related to pleasure, relevance and effort. For EFL classes, Influence was only positively related to effort. Influence was negatively related to confidence in both subject samples. Proximity was positively related to all student outcomes for both subjects, except for achievement where no association was found for physics classes.

Wubbels and Levy [30] discussed subject-related differences in students' and teachers' perceptions comparing data from both the USA and The Netherlands. They found mathematics teachers to be the most dominant of all subject teachers, together with foreign language teachers, while social science teachers were perceived as least dominant. These patterns were found both in students' perceptions as well as in teachers' self-perceptions. Differences were most prominent for the Strict scale (DO) and for the Student Freedom scale (SC). They also interviewed the teachers as to why these differences might have occurred. Teachers argued that in math and foreign language classes, whole-class instruction occurs more often than in other subject classes, requiring stronger adherence to and enforcement of class rules. Moreover, the teachers argued that their subjects required much correcting (in the case of languages both on content and linguistics), resulting in higher dominance (and lower cooperation) perceptions.

\section{RESEARCH QUESTIONS}

So far, only a few studies have been conducted to evaluate subject-specific differences in teacher-student interpersonal relationships involving the science - nonscience dividing line. In this article, the following research questions are investigated:

- What differences in students' perceptions of teacher Influence and Proximity can be found between teachers of science subjects (chemistry, physics, biology and mathematics) and teachers of (all) other subjects?

- What differences in teachers' self-perceptions of teacher Influence and Proximity can be found between teachers of science subjects and teachers of (all) other subjects?
- To what degree can different (distributions of) interpersonal profiles be found in teachers' and students' perceptions of teacher-student interpersonal behavior between science teachers and teachers of (all) other subjects?

\section{METHOD}

\subsection{Sample}

To investigate the above research questions, we reanalyzed an already existing data base on students' and teachers' perceptions of the interpersonal behavior of teachers in Dutch secondary education. The data pertain to QTI data collected during the school years 2004-2005 and 2005-2006. The use of an existing data base implied that only limited information was available with respect to background characteristics of respondents.

Students' perceptions on the QTI were collected with 44,353 students, located in 1,820 classes from 605 teachers in 201 secondary education schools from all across the Netherlands. As such, the dataset contained approximately one third of the total Dutch population of schools. Students were distributed over different school types that are common in the Dutch secondary educational system: 17,547 students were located in the pre-university track (39.6 percent), 12,607 students in the intermediate secondary education track (28.4 percent), and 14,199 in the pre-vocational education track (32.0 percent). In total, 11.7 percent of the students were taught by a teacher in a teacher education program, or by a teacher with less than two years of experience (beginning teachers), the remainder was taught by more experienced teachers. Students were from all grade levels of secondary education (7 though 12 ) with a majority (68.6 percent) located in the first three years.

The teachers of these students taught different school subjects, but 8,503 students $(19.2$ percent $)$ reported perceptions on science teachers; distribution within the science domain were as follows: 1,497 students in Physics classes (17.6 percent), 1,466 students in Chemistry classes (17.2 percent), 3,228 in Biology classes (38.0 percent) and 2,312 in Mathematics classes (27.2 percent). Gender distribution was approximately equal; the sample contained 52.2 percent girls.

Teacher self-perception data were available for most classes in which students' perceptions had been collected, and in some cases self-perception data were available even if no students' perceptions had been gathered. In total, selfperception data were available for 910 teachers and 1,797 of their classes. Distribution across school subjects was as follows: 614 pre-vocational education classes (34.2 percent), 596 intermediate secondary education classes (33.2 percent), and 587 pre-university education classes ( 32.6 percent). The teacher perception sample contained data of 247 beginning teachers' classes, the remainder belonging to classes of experienced teachers. Distribution across school subjects was as follows: 390 science classes (21.7 percent), with 67 Physics classes (17.2 percent of the science subject classes), 72 Chemistry classes (18.5 percent), 148 Biology classes (37.9 percent) and 103 Mathematics classes (26.4 percent). Unfortunately, no information was available on teacher gender. 
Table 1. Number of Items, Reliability and Typical Item for the QTI-Scales

\begin{tabular}{|l|c|c|l|}
\hline \multicolumn{1}{|c|}{ Scale } & $\mathbf{N}_{\text {items }}$ & Alpha (Student Level) & Typical Item \\
\hline \hline DC Leadership & 10 & .83 & S/he is a good leader \\
\hline CD Helpful/friendly & 10 & .88 & S/he is someone we can depend on \\
\hline CS Understanding & 10 & .88 & If we have something to say s/he will listen \\
\hline SC Student freedom & 9 & .80 & S/he gives us a lot of free time in class \\
\hline SO Uncertain & 9 & .80 & S/he seems uncertain \\
\hline OS Dissatisfied & 11 & .87 & S/he is suspicious \\
\hline OD Admonishing & 9 & .81 & S/he gets angry \\
\hline DO Strict & 9 & .71 & S/he is strict \\
\hline
\end{tabular}

\subsection{Instrumentation}

All respondents completed the original, Dutch 77-items version of the QTI $[1,2]$. The psychometric quality of the QTI has been established in a range of studies and is generally accepted as very good [2, 34, 35]. The items are answered on a five-point Likert-type scale. These items are divided into eight scales which conform to the eight sectors of the model. Table 1 presents a typical item and the number of items for each scale.

In the present study we analyzed the teacher-student relationship in terms of dimension scores. To summarize the scale scores by means of dimension scores we use linear combinations of the scale scores. We designate the two linear combinations of the eight scores as an Influence (DS)score and a Proximity (CO)-score. The higher these scores are, the more dominance (DS) or cooperation (CO) is perceived in the behavior of a teacher. In addition to dimension scores we use graphic representations of the eight scale scores ("interpersonal profiles") to report on the teacher-student relationship.

\subsection{Analyses}

To answer the first research question, multilevel analyses of variance were performed with the software package MLN for Windows. In these analyses, three levels were distinguished in the data: a student, teacher-class and school level. Influence (DS) and Proximity (CO) perception scores were used as the dependent variables. Three models were fitted to the data. First, outcomes for empty models were established, showing the amount of variance for each of the two dimensions separately at the three different levels. Next, a subject model was fitted, in which school subject (science versus other subjects) was entered as an independent variable. Finally, a model was fitted in which, apart from school subject, a number of covariates was taken along, namely school type track (two variables, intermediate general secondary education as binary variable (1 meaning the school type to be 'true') and pre-university education as binary variable (pre-vocational education was used as the baseline); student gender ( 1 being male, 0 being female); experience ( 1 being beginning teacher, 0 experienced teacher); and grade level (running from 1 to 6 , higher numbers representing higher grade levels).
In a similar fashion, teacher self-perceptions were also analyzed with multilevel analyses of variance. These analyses contained two levels, being teacher-class and school. Again, three similar types of models were tested. The third model contained only school type track and teacher experience ( 0 being beginner, 1 being experienced) as covariates.

For the third research question, data were first aggregated to the teacher-class level for the student perception data set. Then, scale scores were compared to an existing interpersonal typology $[17,31,32]$ and classes were allocated to the interpersonal profile they most resembled. In a cross-tabular analysis, the distribution of profiles between science classes and other subject classes was compared (using the Chi-squared statistic).

\section{RESULTS}

\subsection{Students' Perceptions of their Teachers}

The outcomes of the multilevel analyses on students' perceptions of their teachers' interpersonal behavior show an interesting pattern. With respect to Influence, it can be seen in Table $\mathbf{2}$ that more than half the variance is related to levels above the student. Science teachers are perceived significantly lower on the Influence dimension, and this remains after the inclusion of covariates. The results also show that pre-university students perceive their teachers as less dominant, that boys perceive their teachers as less dominant than girls do, that beginning teachers are perceived lower in terms of dominance compared to their more experienced colleagues and that students in the higher grade levels also perceive less dominance than students in lower grade levels. The difference in perception between science teachers and other teachers is quite strong; it explains 1.2 percent of the total variance (which corresponds to one third of the total variance explained by all variables). Moreover, the effect size of school-subject is equally high as that of school type track (pre-university) and grade level, but higher than the effect size of gender.

Table $\mathbf{3}$ shows that variance distribution between levels is roughly similar for Proximity. Science teachers are not perceived lower on the Proximity dimension compared with colleagues of other subjects when school-subject is considered the only explanatory variable. However, the science teachers are perceived significantly lower on 
Table 2. Student Perceptions of Influence (DS) Regression Coefficients Significant (at $\alpha=.05)$ and Variance Components

\begin{tabular}{|c|c|c|c|c|c|}
\hline & Variables & Empty Model & Subject Model & Teaching Model & Effect Size \\
\hline & Constant & .13 & .15 & .27 & \\
\hline & Subject (1=science) & & -.11 & -.07 & -.07 \\
\hline & $\begin{array}{l}\text { School type (intermediate) } \\
\text { School type (pre-university) } \\
\text { Gender (1=male) } \\
\text { Experience (1=beginner) } \\
\text { Grade }\end{array}$ & & & $\begin{array}{r}-.01(\mathrm{~ns}) \\
-.05 \\
.01 \\
-.17 \\
-.03\end{array}$ & $\begin{array}{r}-.01 \\
-.06 \\
.01 \\
-.13 \\
-.09\end{array}$ \\
\hline Variance & $\begin{array}{l}\text { School } \\
\text { Class } \\
\text { Student } \\
\text { Explained }\end{array}$ & $\begin{array}{r}10.1 \% \\
40.2 \% \\
49.7 \% \\
-\end{array}$ & $\begin{array}{r}8.9 \% \\
40.2 \% \\
49.7 \% \\
1.2 \%\end{array}$ & $\begin{array}{r}8.4 \% \\
38.0 \% \\
49.7 \% \\
3.9 \%\end{array}$ & \\
\hline$-2 \log ($ like $)$ & & 23582.95 & 23566.15 & 23438.11 & \\
\hline Difference $\log (\mathrm{df})$ & & - & $16.80(1)$ & $128.04(9)$ & \\
\hline
\end{tabular}

Table 3. Student Perceptions of Proximity (CO) Regression Coefficients Significant (at $\alpha=.05)$ and Variance Components

\begin{tabular}{|c|c|c|c|c|c|}
\hline & Variables & Empty Model & Subject Model & Teaching Model & Effect Size \\
\hline & Constant & .68 & .69 & .55 & \\
\hline & Subject $(1=$ science $)$ & & $-.04(\mathrm{~ns})$ & -.09 & -.05 \\
\hline & $\begin{array}{l}\text { School type (intermediate) } \\
\text { School type (pre-university) } \\
\text { Gender (1=male) } \\
\text { Experience (1=beginner) } \\
\text { Grade }\end{array}$ & & & $\begin{array}{r}.03(\mathrm{~ns}) \\
.10 \\
-.07 \\
.06(\mathrm{~ns}) \\
.05\end{array}$ & $\begin{array}{r}.02 \\
.07 \\
-.05 \\
.03 \\
.10\end{array}$ \\
\hline Variance & $\begin{array}{l}\text { School } \\
\text { Class } \\
\text { Student } \\
\text { Explained }\end{array}$ & $\begin{array}{r}2.6 \% \\
43.8 \% \\
53.6 \% \\
-\end{array}$ & $\begin{array}{r}2.6 \% \\
43.8 \% \\
53.6 \% \\
0.0 \%\end{array}$ & $\begin{array}{r}4.2 \% \\
44.0 \% \\
53.1 \% \\
0.4 \%\end{array}$ & \\
\hline$-2 \log ($ like $)$ & & 67458.24 & 67457.23 & 67128.65 & \\
\hline Difference $\log (\mathrm{df})$ & & - & $1.01(1)(\mathrm{ns})$ & $328.58(9)$ & \\
\hline
\end{tabular}

Proximity after inclusion of all covariates in the model. Students in higher grade levels and pre-university students perceive more Proximity than younger students and students in other tracks, boys perceive less Proximity then girls. With Proximity, however, the effect of school subject is not very strong. It explains no variance in the Proximity score and its effect size is equal or lower compared with the effect sizes of the other (significant) covariates.

\subsection{Teachers' Self Perceptions}

Table 4 seems to suggest that science teachers perceive themselves slightly (but significantly) lower on the Influence dimension. However, the school-subject effect disappears after the inclusion of covariates. Moreover, the effect size of subject taught is marginal and the total amount of variance explained in Influence is minimal (0.6 percent).

In Table 5 it can be seen that teachers in the science subjects perceive themselves similar to teachers of other subjects when that is considered as the only explanatory variable, but they perceive themselves significantly less cooperative when other covariates are entered into the model. Although the overall effect of subject taught seems to be minimal (no variance is explained), its effect size is larger than the effect size of all other covariates.

\subsection{Interpersonal Profiles}

The findings of the multilevel analyses are to some degree reflected in a comparison of interpersonal profiles between science teachers and teachers of other subjects. A significant difference in distribution over the eight profiles is found between science teachers and the other teachers (Table 6).

It appears that science teachers are relatively less often perceived as Directive, Authoritative or Tolerant/Authoritative compared with teachers of other subjects, but relatively more often as Tolerant and Uncertain/Tolerant. In a similar 
Table 4. Teachers Self Perceptions of Influence (DS) Regression Coefficients Significant (at $\alpha=.05)$ and Variance Components

\begin{tabular}{|c|c|c|c|c|c|}
\hline & Variables & Empty Model & Subject Model & Teaching Model & Effect Size \\
\hline & Constant & .15 & .15 & .19 & \\
\hline & Subject $(1=$ science $)$ & & -.002 & $-.001(\mathrm{~ns})$ & -.001 \\
\hline & $\begin{array}{l}\text { School type (intermediate) } \\
\text { School type (pre-university) } \\
\text { Experience (1=beginner) }\end{array}$ & & & $\begin{array}{r}.00(\mathrm{~ns}) \\
.00(\mathrm{~ns}) \\
-.30\end{array}$ & $\begin{array}{r}.00 \\
.00 \\
-.25\end{array}$ \\
\hline Variance & $\begin{array}{l}\text { School } \\
\text { Class } \\
\text { Explained }\end{array}$ & $\begin{array}{r}100.0 \% \\
0.0 \% \\
-\end{array}$ & $\begin{array}{r}99.4 \% \\
0.0 \% \\
0.6 \%\end{array}$ & $\begin{array}{r}93.4 \% \\
0.0 \% \\
6.6 \% \\
\end{array}$ & \\
\hline$-2 \log ($ like $)$ & & -517.90 & -522.98 & -622.93 & \\
\hline Difference $\log (\mathrm{df})$ & & - & $5.08(1)$ & $99.95(3)$ & \\
\hline
\end{tabular}

Table 5. Teachers Self Perceptions of Proximity (CO) Regression Coefficients Significant (at $\alpha=.05)$ and Variance Components

\begin{tabular}{|c|c|c|c|c|c|}
\hline & Variables & Empty Model & Subject Model & Teaching Model & Effect Size \\
\hline & Constant & .88 & .89 & .89 & \\
\hline & Subject ( $1=$ science) & & $-.04(\mathrm{~ns})$ & -.09 & .08 \\
\hline & $\begin{array}{l}\text { School type (intermediate) } \\
\text { School type (pre-university) } \\
\text { Experience (1=beginner) }\end{array}$ & & & $\begin{array}{r}-.04(\mathrm{~ns}) \\
.04 \\
.07(\mathrm{~ns})\end{array}$ & $\begin{array}{r}-.04 \\
.05 \\
.05\end{array}$ \\
\hline Variance & $\begin{array}{l}\text { School } \\
\text { Class } \\
\text { Explained }\end{array}$ & $\begin{array}{r}77.1 \% \\
22.9 \% \\
-\end{array}$ & $\begin{array}{r}77.1 \% \\
22.9 \% \\
0.0 \%\end{array}$ & $\begin{array}{r}76.6 \% \\
22.9 \% \\
0.5 \%\end{array}$ & \\
\hline$-2 \log ($ like $)$ & & 1837.16 & 1834.45 & 1820.08 & \\
\hline Difference $\log (\mathrm{df})$ & & - & $2.71(1)(\mathrm{ns})$ & $14.37(3)$ & \\
\hline
\end{tabular}

fashion, science teachers perceive themselves relatively less often as Authoritative or Tolerant/Authoritative, but relatively more often as Tolerant, Uncertain/Tolerant and to some degree Uncertain/Aggres-sive. Fig. (3) shows that same results on students' perceptions in a circular plot which allows the easy interpretation that the average science teachers' position seems to be shifted towards the lower left quadrant.

Table 6. Distribution of Interpersonal Profiles for Science Classes and Other Subject Classes (within Subject Group Percentages Shown in Brackets)

\begin{tabular}{|c|c|c|c|c|}
\hline Profile & \multicolumn{2}{|c|}{ Student Perceptions } & \multicolumn{2}{|c|}{ Teacher Self-Perceptions } \\
\hline Directive & $30(10.0)$ & $245(16.1)$ & $39(10.5)$ & $204(13.6)$ \\
\hline Authoritative & $32(10.6)$ & $332(21.9)$ & $63(16.9)$ & $369(24.6)$ \\
\hline Tolerant/authoritative & $47(15.6)$ & $263(17.3)$ & $71(19.0)$ & $380(25.3)$ \\
\hline Uncertain/tolerant & $57(18.9)$ & $172(11.3)$ & $51(13.7)$ & $119(7.9)$ \\
\hline Uncertain/aggressive & $18(5.9)$ & $67(4.4)$ & $10(2.7)$ & $14(0.9)$ \\
\hline Repressive & $-(0.0)$ & $25(1.6)$ & $1(0.3)$ & $16(1.1)$ \\
\hline Drudging & $23(7.6)$ & $109(7.2)$ & $11(2.9)$ & $44(2.9)$ \\
\hline
\end{tabular}




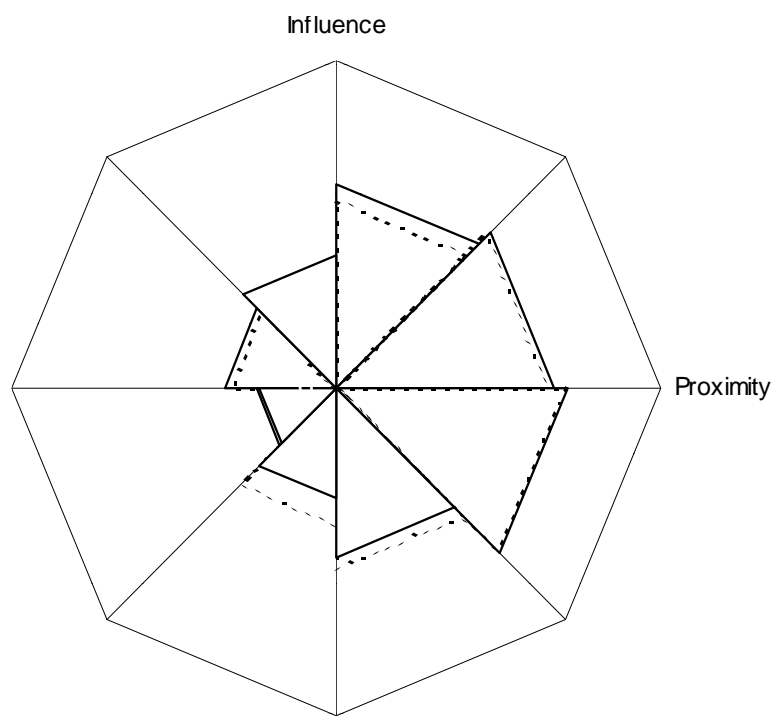

Fig. (3). Profile of science teachers (dotted line) and teachers of other subjects (fixed line).

\section{CONCLUSION AND DISCUSSION}

This study investigated differences in perceptions of teachers and students regarding teachers' interpersonal behavior between science teachers and other subject teachers. For this purpose, a large existing data base was reanalyzed with multilevel analyses of variance, correcting the effect of subject for other covariates. Classroom patterns of interpersonal relationships were categorized within eight types as well.

Some differences in student perceptions were found related to subject taught. Science teachers were perceived as less dominant and less cooperative (only after correction for covariates). These patterns were also found in teachers' selfperceptions, though less pronounced and again only after correction for covariates. Nevertheless, our findings seem to converge with the few previous studies investigating this topic (though often with less advanced means and smaller data sets), such as the studies by den Brok et al. [20] and Levy et al. [21].

Several explanations may explain these differences. As mentioned in the introduction section, students may hold different and prototypical views of their science teachers sometimes even taking the form of prejudices - and hence project negative views onto their perceptions [24-27]. Another explanation might lie in differences in the beliefs of teachers regarding (teaching) their subject; it has been suggested that science teachers are more subject-oriented and less student-oriented than teachers of other subjects [28]. Yet another explanation might lie in the learning activities and classroom organization initiated by teachers. Prior studies suggest that in some subjects, such as math and physics, more whole-class teaching and use of small problem-solving tasks may be observed, which again might result in differences in interaction patterns and hence perceptions of the teacher-student interpersonal relationship [30]. However, since the present study did not collect any data from students or teachers regarding their attitudes and beliefs regarding the subject and teaching methods, all of these explanations remain speculative. Future research could shed more light on this issue.
Our results also show that subject-related differences sometimes may be hidden behind (or overlap with) other variables. For researchers it is important to realize that differences in perceptions that appear to relate to gender (or gender distribution in classroom), teacher experience or school type sometimes may actually be differences that can be attributed to the subject taught. Although subject-related differences appeared to have modest effects on perceptions they appeared as separate effects nevertheless. Though such effects explained numerically small portions of variance, these effects are practically significant since the effect sizes are in the same order or larger than for instance gender or school-type effects.

The result can alternatively be expressed by stating that the interpersonal profiles of science teachers are significantly less often Directive, Authoritative or Tolerant-Authoritative, and more often Tolerant or Uncertain/Tolerant. These interpersonal styles are known to be associated with particular learning outcomes [33]. Tolerant or Uncertain/ Tolerant styles, which are relatively abundant with science teachers, are associated with moderate student attitudes. The Authoritative and Directive styles are associated with positive attitudes towards the subjects, but these are less abundant with science teachers. Hence, science teachers' interpersonal style may be an element contributing to the low attitudes toward the sciences found in many modern western countries [36].

We did not investigate differences between the various (science) subjects and concentrated on the science - nonscience watershed. Future research could investigate such differences. Relevant differences may exist and a next possible step in our endeavors might lie in a more detailed analysis of subject differences and in relating such differences to variables such as curriculum content or structure and lesson time available for the subject, among other possible variables. Such future studies would require the collection of original data and might include new subjects. A study comparing students' perceptions of Turkish science students between Biology, Chemistry and Physics found, for example, significant differences between these 
subjects, with Physics teachers being perceived lower on both interpersonal dimensions compared to teachers of the other two subjects [37]. One may wonder whether similar differences will be found in other cultures or countries, such as The Netherlands.

Another possible next step might be the creation of a new study, linking perceptions of teachers and students to other relevant variables such as beliefs in the subject and the knowledge involved in the subject, stereotypical images in students' and teachers' beliefs in their subject and subject teachers, a wider variety of personality and personal background characteristics, etc. Moreover, such studies could be conducted including a variety of research methods, such as interviews with students and teachers, rep-grids, concept mapping, etc.

The results provide several suggestions for policy and practice. Because of the consistency of the differences found in teacher-student interpersonal relationsips between science and non-science classes, it seems wise for teacher education and professional development programmes to pay more attention to the nature of the subject as explanatory factor for teacher-student interactions in order to make student teachers aware of these differences. In relation to creating such awareness other topics should be addressed as well, such as differences in beliefs and attitudes that teachers and students may hold and the effect of these views on teacher-student interaction and perceptions. The results also suggest that paying extra attention to the interpersonal competence of teachers in science teacher education programmes may be beneficial, as training verbal and non-verbal behaviors related to high proximity and influence may lead to different perceptions of the teacher-student interpersonal relationship. Instruments such as the QTI may be helpful in this process, as they help student teachers to reflect on their own perceptions, those of their students and differences between these, and because they provide an instant picture of the relationship that is easy to grasp.

\section{ACKNOWLEDGEMENTS}

The authors would like to thank Theo Wubbels and Mieke Brekelmans at Utrecht University for allowing us to (re)analyse part of a larger dataset on student and teacher perceptions of teacher-student interpersonal behaviour collected with the QTI.

\section{REFERENCES}

[1] Wubbels T, Créton HA, Hooymayers, HP. Discipline problems of beginning teachers, interactional behavior mapped out. Paper presented at the American Educational Research Association annual meeting: Chicago, United States 1985.

[2] Wubbels Th, Créton HA, Brekelmans M, Hooymayers, HP. Perceptions of the teacher-student relationship. Tijdschrift voor Onderwijsresearch 1987; 12(1): 3-16.

[3] Leary T. An interpersonal diagnosis of personality. New York: Ronald Press Company 1957.

[4] Brekelmans M, Holvast A, van Tartwijk J. Changes in teacher communication styles during the professional career. J Classroom Interact 1992; 27(1): 13-22.

[5] den Brok P, Fisher D, Koul, R. The importance of teacher interpersonal behaviour for secondary science students in Kashmir. J Classroom Interact 2005; 40(2): 5-19.

[6] den Brok P, Levy J, Brekelmans M, Wubbels T. The effect of teacher interpersonal behaviour on students'subject-specific motivation. J Classroom Interact 2005; 40(2): 20-33.
[7] Khine MS, Fisher DL. Teacher-student interactions in science classrooms in Brunei. J Classroom Interact 2003; 38(2): 21-28.

[8] Kremer-Hayon L, Wubbels Th. Interpersonal relationships of cooperating teacher and student teachers' satisfaction with supervision. J Classroom Interact 1992; 27(1): 31-38.

[9] Kyriakides L. Drawing from teacher effectiveness research into teacher interpersonal behaviour to establish a teacher evaluation system: a study on the use of student ratings to evaluate teacher behaviour. J Classroom Interact 2005; 40(2): 44-66.

[10] Lang QC, Wong AFL, Fraser BJ. Teacher-student interaction and gifted students' attitudes toward chemistry in laboratory classrooms in Singapore. J Classroom Interact 2005; 40(1): 18-28.

[11] Lapointe J. Teacher-student conflict and misbehavior: toward a model of the extended symmetrical escalation. J Classroom Interact 2003; 38(2): 11-16.

[12] Levy J, Wubbels Th. Student and teacher characteristics and perceptions of teacher communication style. J Classroom Interact 1992; 27(1): 23-30.

[13] Mellor DJ, Moore KA. The questionnaire on teacher interaction: assessing information transfer in single- and multi-teacher environments. J Classroom Interact 2003; 28(2): 29-35.

[14] Sztejnberg A, den Brok P, Hurek J. Preferred teacher-student interpersonal behaviour: differences between polish primary and higher education students' perceptions. J Classroom Interact 2004; 39(2): 32-40.

[15] Van Petegem K, Creemers BPM, Rosseel Y, Aelterman A. Relationships between teacher characteristics, interpersonal teacher behaviour and teacher wellbeing. J Classroom Interact 2005; 40(2): 34-43.

[16] Wubbels T, Créton HA, Hooymayers HP. Review of research on teacher communication styles with use of the leary model. J Classroom Interact 1992; 27(1): 1-11.

[17] Wubbels Th, Brekelmans M, den Brok P, van Tartwijk J. An interpersonal perspective on classroom management in secondary classrooms in the Netherlands. In: Evertson C, Weinstein CS, Eds. Handbook of classroom management: research, practice and contemporary issues. NJ, MahWah: Lawrence Erlbaum Associates 2006; pp. 1161-91.

[18] Wubbels Th, Brekelmans M. Two decades of research on teacherstudent relationships in class. Int J Educ Res 2005; 43: 6-24.

[19] Wubbels T, Brekelmans M. The teacher factor in the social climate of the classroom. In: Fraser BJ, Tobin KG, Eds. Int Handb Sci Edu. NJ, MahWah: Lawrence Erlbaum Associates 1998; pp. 565-80.

[20] den Brok P, Brekelmans M, Wubbels T. Interpersonal teacher behaviour and student outcomes. Sch Eff Sch Improv 2004; 15(3/4): 407-42.

[21] Levy J, den Brok P, Wubbels T, Brekelmans M. Students' perceptions of interpersonal aspects of the learning environment. Learn Environ Res 2003; 6(1): 5-36.

[22] Dekkers J, Delaeter J. Enrolment in school science education in Australia. Int J Sci Educ 2001; 23: 487-500.

[23] OECD. Evolution of student interest in science and technology (Studies Policy Report 16-30). Retrieved 2008 February 4 from website: http://www.oecd.org/dataoecd/16/30/36645825.pdf.

[24] Taconis R, Kessels U. Does science suit me? How perceived cultural prototypes influence students' commitment to a school subject. Paper presented at the 12th European EARLI conference. Budapest, Hungary 2007.

[25] Aikenhead GS. Review of research on humanistic perspectives in science curricula. Paper presented at the NARST conference. New Orleans, MI 2003.

[26] Gaskell PJ. Authentic science and school science. Int J Sci Educ 1992; 14: 265-72.

[27] Knain E. Ideologies in school science textbooks. Int J Sci Educ 2001; 23: 319-29.

[28] Beijaard D, Verloop N, Vermunt JD. Teachers' perceptions of professional identity: an exploratory study from a personal knowledge perspective. Teach Teach Educ 2000; 16(7): 749-64.

[29] Cronin-Jones LL. Science teacher beliefs and their influence on curriculum implementation: two case studies. J Res Sci Teach 1991; 28(3): 235-50

[30] Wubbels T, Levy J, Eds. Falmer press: do you know what you look like? London: The Falmer Press 1993.

[31] Brekelmans M, Levy J, Rodriguez R. A typology of teacher communication style. In: Wubbels T, Levy J, Eds. Do you know what you look like? London: The Falmer Press 1993; pp. 46-55. 
[32] Wubbels T, Brekelmans M, Hermans J. Teacher behavior: an important aspect of the learning environment. In: Fraser BJ, Ed. The study of learning environments. Perth: SMEC/Curtin Unversity 1987; vol. 3: pp. 10-25.

[33] Brekelmans M, Wubbels T, Levy J. Student performance, attitudes, instructional strategies and teacher-communication style. In: Wubbels T, Levy J, Eds. Do you know what you look like? London: The Falmer Press 1993; pp. 46-55.

[34] Wubbels Th, Levy J. A comparison of interpersonal behavior of Dutch and American teachers. Int J Intercult Relatsh 1991; 15: 118.
[35] den Brok P, Brekelmans M, Wubbels T. Multilevel issues in studies using students' perceptions of learning environments: the case of the Questionnaire on Teacher Interaction. Learn Environ Res 2006; 9(3): 199-213.

[36] Lyons T. Different countries, same science classes: students' experiences of school science in their own words. Int J Sci Educ 2006; 28(6): 591-613

[37] Telli S. Students' perceptions of their science teachers' interpersonal behaviour in two countries: Turkey and the Netherlands. PhD [dissertation]. Ankara: Middle East Technical University 2006.

(C) den Brok et al.; Licensee Bentham Open.

This is an open access article licensed under the terms of the Creative Commons Attribution Non-Commercial License (http://creativecommons.org/licenses/by-nc/ 3.0/) which permits unrestricted, non-commercial use, distribution and reproduction in any medium, provided the work is properly cited. 